\title{
Investigating the Effects of the Block Geometries and Sidewall Divergences on the Local Scour Downstream of Baffled Chute Spillways
}

\author{
Morteza Karimi Chahartaghi, ${ }^{1}$ Sohrab Nazari $\left(\mathbb{D},{ }^{2}\right.$ and Mohsen Solimani Babarsad ${ }^{1}$ \\ ${ }^{1}$ Department of Civil Engineering- Water Resources Engineering and Management, Shoushtar Branch, Islamic Azad University, \\ Shoushtar, Iran \\ ${ }^{2}$ Department of Civil Engineering, Eghlid Branch, Islamic Azad University, Eghlid, Iran
}

Correspondence should be addressed to Sohrab Nazari; nazari.soh@gmail.com

Received 3 September 2019; Revised 6 August 2020; Accepted 1 September 2020; Published 15 October 2020

Academic Editor: Kirk Hatfield

Copyright (c) 2020 Morteza Karimi Chahartaghi et al. This is an open access article distributed under the Creative Commons Attribution License, which permits unrestricted use, distribution, and reproduction in any medium, provided the original work is properly cited.

\begin{abstract}
Due to the lack of any specific study about the sidewalls and other blocks' changes in the case of hydraulic and scour downstream, the present study was conducted to investigate this issue. For this purpose, drainage projects and spillway chutes, as well as many baffle block chutes, were designed and constructed with the parallel sidewalls and trapezoidal shape using the U.S. Bureau of Reclamation (USBR) instructions. Three divergence ratios of $\left(\left(b_{1} / b_{2}\right)=1.45,1.75\right.$, and 2.45), a parallel sidewall of $\left(b_{1} / b_{2} n=q 1\right)$, and also three geometry blocks including trapezoidal USBR, trihedral, and semicircle blocks were applied and tested in the hydraulic laboratory using a baffle chute with the slope of $(2: 1),(\mathrm{H}: \mathrm{V})$. The material used in this study was sediment sand with a uniform grain size of $d_{50}=1.2 \mathrm{~mm}, 15 \mathrm{~cm}$ of thickness, and $2 \mathrm{~m}$ of length. The experiment was conducted with seven different discharges in lasting condition, and the flow characteristic and scour hole dimensions were measured. The results revealed that in comparison with the USBR blocks, changes in the baffle sidewall and block shape made an approximate $50 \%$ reduction in the maximum depth of the scour hole. Thus, increasing the divergence ratio from 1 to 2.45 had a significant effect on reducing the maximum depth and the topographic shape of the scour hole. According to the range mentioned in the literature for the Weber number, the scale effect was negligible for the chute with baffle blocks. Generally, it can be concluded that the sidewall changes also can make a reduction in the number of overbaffle blocks, causing a reduction in the construction cost.
\end{abstract}

\section{Introduction}

Erosion and scour downstream of the hydraulic structures have always been a matter of concern for the hydraulic engineers and researchers in this field. In addition to causing the instability in the structures and rivers' side walls, erosion downstream of the hydraulic structures may disrupt the function of the structures through changes in the river topography. Spillways are among the most vulnerable structures in this regard as they are usually exposed to the high-speed and high-energy currents with a high potential of erosion and destruction downstream of the spillways. $\mathrm{Nu}$ merous studies have been conducted on the scour and its various aspects, such as energy dissipation downstream of the structures [1-3]. D'Agostino and Ferro [4] reviewed the studies conducted by Bormann and Julien [1] on the scour downstream of the control structures. Dargahi [5] experimentally studied the scour downstream of a spillway with an apron installed at the end of the spillway on the surface of the sediments. According to their results, secondary flows downstream of the spillway formed several scour holes, which were gradually developed and incorporated. Rock blocks can be used to enhance the energy dissipation on the ramp $[6,7]$. Zare and Doering [3] studied the effect of adding the baffles and end sills on the energy dissipation of flow over stepped spillways with sharp or round edges and an ogee inlet. They concluded that the energy dissipation ratio for baffle-edged chutes was higher than the still-edged chutes. 
Also, the mentioned ratio was higher for rounded-stepped spillways in comparison with the sharp-stepped spillways. A chute structure with baffled blocks is considered a flow energy dissipator of impact type. As Peterka [8] describes, "The baffled apron is not a device to reduce the velocity of the incoming flow; rather, it is only intended to prevent the excessive acceleration of the flow passing down the chute" [8]. This structure was primarily suggested for a maximum discharge of $5.6 \mathrm{~m}^{3} / \mathrm{s}$ per unit width [8]. However, according to the experiments conducted by other researchers, this structure was later proposed for use at higher discharge rates employing the dam spillway hydraulic models [9]. The United States Bureau of Reclamation (USBR) has conducted extensive studies on the baffle block chutes to achieve an optimal design. The USBR guidelines have recommended a slope of $(2: 1)$ for the chutes [8]. Figure 1 displays the details of a chute structure with baffle blocks.

Tuna [11] studied the effect of the inlet channel angle of the stepped spillways relative to the horizon on the erosion downstream of the spillways and found an optimal angle of $30^{\circ}$. Elnikhely [12] investigated the effect of the cylindrical blocks installed on the ramp downstream of the spillway on the dimensions of the scour hole downstream of the blocks. They determined the effect of the size and arrangement of the cylindrical blocks at different discharges to obtain the optimal geometry and arrangement of the cylinders. Kaya and Emiroglu [10] investigated the effect of the stepped, wedge, T-shaped, and trapezoidal blocks at different chute bed slopes from $1: 4.24$ to $1: 0.73$ on the energy dissipation of the flow passing over this structure. According to their results, T-shaped blocks outperformed other geometries in terms of the enhanced energy dissipation and oxygen level.

Oliverto and Comuniello [13] experimentally studied the local scour downstream of a positive-step stilling basin. The basin length, sediment grading, and temporal variations in the equilibrium scour hole were studied from $2 \mathrm{~h}$ to 3 days. The maximum scour depth and the quasiequilibrium scour hole length were measured, and the temporal progress of the scour and longitudinal scour profile were also investigated. They found that it took 3 days to attain a quasiequilibrium scour hole. The tailwater depth significantly influenced the equilibrium time and scour parameters. Some correlations were provided for each parameter in terms of the Froude number, and the equations proposed by Farhoudi and Smith [2] were optimized.

Tuna and Emiroglu [14] studied the effect of the step geometry on the local scour downstream of the stepped chutes (spillways). The effect of maximum scour depth, scour hole length, and also scoured bed topography was evaluated. Their results showed that the scour hole dimensions are a function of the step geometry, sediment grain size, flow rate, spillway angle, and water level downstream. The maximum scour depth was decreased by decreasing the step height. Step dimensions significantly influenced the scour depth at downstream. The ratio of the maximum scour depth to the step height was increased by increasing the discharge per unit width. The ratio of the scour length to the step height was increased by increasing the step height to length ratio.

Oliveto [15] conducted a study entitled the "Local Scouring Downstream of a Spillway with an Apron". Experiments were carried out on a mobile scoured sedimentary bed from 48 to $196 \mathrm{~h}$. Some experiments were also conducted in short times from 1 to $3 \mathrm{~h}$. The experimental results indicated that the dimensionless scour depth is dependent on the tailwater depth, Froude number, dimensionless time function, and placement of the hydraulic jump on the bed floor. Some correlations were proposed to estimate the scour depth dimensions based on the effective parameters.

Michael and Hubert [16] studied the two-phase water-air flows and scale effects in the hydraulic models. In the free surface flows, the gravity and inertia forces were considered in the simulation based on the Froude number, while surface tension and viscous forces were also effective in the twophase flows. Accordingly, the Weber and Reynolds numbers should also be considered. The model scale should be considered large enough for being capable of estimating the two-phase flow reasonably to evaluate the two-phase flows, according to the air bubble size and turbulence conditions. The Morton number was used as a criterion to reduce the scale effect. The ranges for the Weber and Reynolds numbers were also suggested to reduce the scale effect.

The structure is constructed in the divergent form with a variable width due to the spatial limitations in some circumstances. Furthermore, efforts for enhancing the efficiency of such structures have led to the use of the blocks of various geometries. According to the review of the literature, there is no fundamental study on the performance, namely, the scour downstream of the baffled chutes with divergence sidewall and also the blocks suggested in the present study. Therefore, this study was conducted to investigate the effect of the divergence of the sidewall in the baffled chutes with three geometry blocks including the semicircular and trihedral blocks and trapezoidal piers (USBR) on the dimensions and topography of the scour hole. For this purpose, parallel and divergent sidewall laboratory models were developed with different block shapes and were tested at seven discharge rates.

\section{Materials and Methods}

2.1. Dimensional Analysis. The tested parameters are presented in the following equation:

$$
f\left(\varphi, F r_{0}, d_{s}, L_{s}, V_{s}, H, y_{c}, b_{2}, b_{1}, h_{b}, h_{t}\right)=0,
$$

where $\left(F r_{0}\right)$ is the Froude number of the flow upstream in the spillway, $\left(d_{s}\right)$ represents the mean and maximum scour depth, $\left(L_{s}\right)$ denotes the scour hole length, $\left(V_{s}\right)$ is the scour hole volume, $(H)$ shows the head upstream of the spillway in 


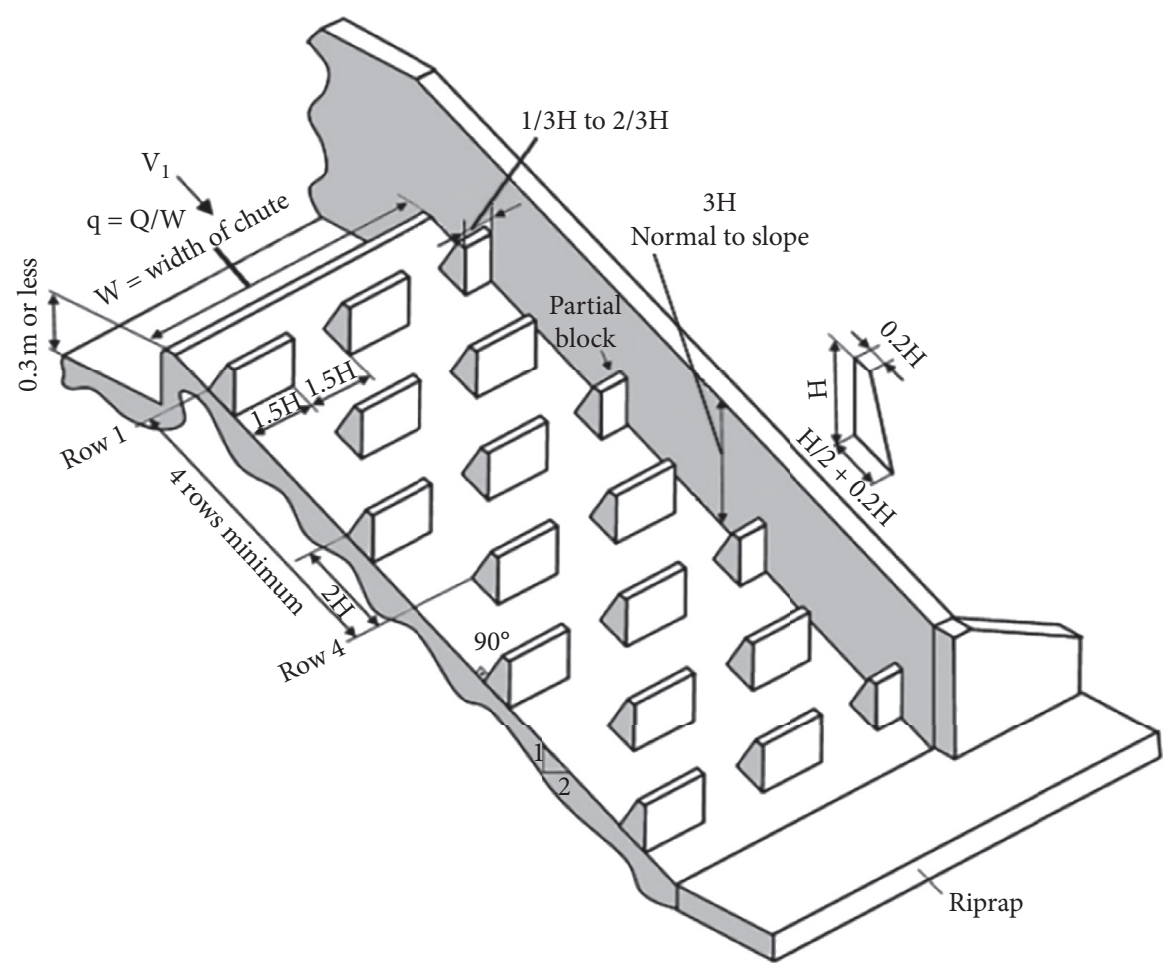

Figure 1: The components of a chute with trapezoidal baffle blocks [10].

the reservoir, $\left(y_{c}\right)$ refers the critical depth of flow over the spillway, $\left(b_{2}\right)$ is the spillway width downstream of the chute, $\left(b_{1}\right)$ denotes the spillway width upstream of the inlet, and $\left(h_{b}\right)$ represents the block height $\left(h_{t}\right)$ of tailwater. According to the dimensional analysis by $\pi$-Buckingham theorem, the following equation shows the relationship between the scour hole parameters downstream of the chute and baffle blocks:

$$
\frac{d_{s}}{H}, \frac{L_{S}}{H}=f\left(\frac{y_{c}}{H}, F r_{0}, \frac{b_{2}}{b_{1}}, \frac{h_{b}}{H}, \frac{h_{t}}{H}\right) \text {. }
$$

Considering the sedimentary material grading and hydraulic conditions, such as the tailwater depth (ht) to be constant, the effects of these two parameters were not discussed in this study. However, the effects of other parameters, including the tailwater depth (ht) controlled by the end gate of the channel, sediment grading, and the time to attain an equilibrium scour hole, have been considered in other studies conducted on this model. In this study, the effects of block type and shape and the sidewall angle of the structure are considered by assuming other conditions constant. Studies are also underway to investigate the effects of dynamic pressure, cavitation around the blocks, two-phase airwater flow, and velocity variations and water surface profile along the chute.

\section{Apparatus and Methods}

3.1. Modeling Details of the Chute with Baffle Blocks. Chutes with baffle blocks are among the structures used for dissipating the energy, in which the blocks control the velocity and reduce the flow acceleration. The flow energy is controlled and dissipated through collision with the blocks and passing through or over the blocks. This structure is usually constructed for the emergency discharge of flow in the irrigation and drainage network before using the inverted siphon or any other structure to transfer the flow in the main channel temporally as a lateral structure to the natural conduits, such as rivers and flood channels after being disconnected by the control gates. One type of this structure was constructed in the irrigation and drainage network on the Doroodzan Dam in the north of Fars province, Iran. It was established on a channel on the left side of the Ramjerd Plain before the Junaki inverted siphon to discharge water in the main channel during the inverted siphon maintenance or when the flow should be discharged for disconnection in the emergency. The main challenge facing this type of structure in scouring downstream of the structure occurs when the flow is discharged to the natural rivers. Figures 2(a) and 2(b) show the main USBR chute structure with baffle blocks of the irrigation and drainage network on the Doroodzan Dam, Fars province, Iran (Junaki inverted siphon) with a longitudinal slope of $2: 1$ (horizontal: vertical). The inflow to the structure is controlled by a sill with a height of $50 \mathrm{~cm}$ to reduce the flow velocity. Blocks with a height of $90 \mathrm{~cm}$ were considered in accordance with the USBR regulation for a discharge of $28 \mathrm{~m}^{3} / \mathrm{s}$ and the design type $(H=0.8-0.9 \mathrm{dc})$. The critical depth $(\mathrm{dc})$ was calculated from the following equation (3) where $Q$ represents the discharge per unit width:

$$
d_{c}=\sqrt[3]{\frac{q^{2}}{g}}
$$




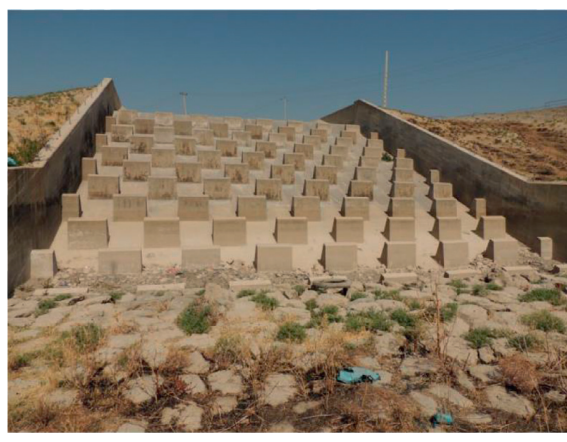

(a)

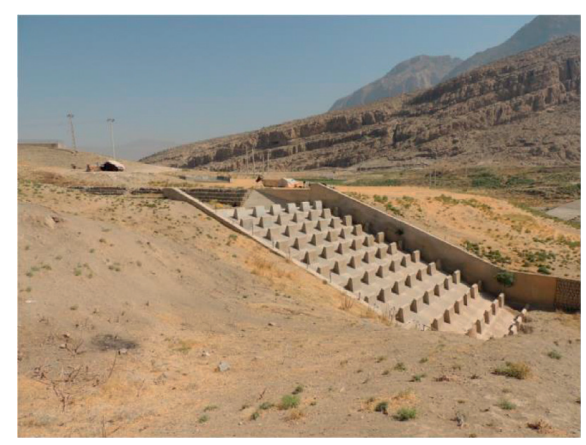

(b)

Figure 2: The main chute structure with baffle blocks of the irrigation and drainage network on the Doroodzan Dam, Fars province, Iran (the side outlet of Junaki inverted siphon).

Experiments were conducted in a laboratory channel equipped with a water circulation system with a width of $1 \mathrm{~m}$, a length of $6 \mathrm{~m}$, and a height of $1.2 \mathrm{~m}$ (Figure 3). Water was injected into the system by a $5^{\prime \prime}$ centrifugal pump. A honeycomb baffle was installed at the channel inlet for flow laminarization. After passing over the chute model, the flow was transferred to an underground tank to be recirculated by the centrifugal pump. The discharge rate was measured by an electromagnetic flowmeter with an accuracy of $0.01 \mathrm{~L} / \mathrm{s}$.

\subsection{Properties of the Sedimentary Materials Used Downstream} of the Chute Structure. The sedimentary sand composing of relatively uniform grains and $d 50$ was used with the average diameter of particles to investigate the scour of sediments downstream of the chute, sand sediments with specific gravity $\mathrm{Gs}=2.67$, and diameters $\left(d_{10}=0.75, d_{16}=0.8\right.$, $d_{30}=0.92, d_{60}=1.28$, and $d_{84}=1.34 \mathrm{~mm}$ ), coefficient of uniformity $C u=1.70$ and coefficient of curvature $C c=0.94$, and geometric standard deviation $\sigma g=1.29$ (since the geometric standard deviation is less than $1.33(\sigma g=1.29))$ [17]. According to Raudkivi and Ettema [18], an average diameter of $0.7 \mathrm{~mm}$ was considered for the sedimentary particles to prevent the ripple formation on the sedimentary surface. Accordingly, an average particle diameter (d50) of 1.2 will not cause the ripple formation. Also, the height of the bed material was equal to $0.15 \mathrm{~m}$, with a length of $2 \mathrm{~m}$, and a width of $0.975 \mathrm{~m}$.

The wooden baffle piers were constructed and placed on the model according to the dimensions specified in the USBR guidelines, as presented in Figure 4. Ten labyrinth block rows were considered on the chutes. The approaching velocity over the chute should be sufficiently lower than the critical velocity. A short stilling basin with an end step of height $5 \mathrm{~cm}$ was considered to establish a laminar flow at the chute model inlet. The head along the upstream and downstream of the divergent chute was measured by a point level gauge with an accuracy of $0.1 \mathrm{~mm}$. A block height of $4.5 \mathrm{~cm}$ was considered in all the models.

Four divergence ratios of $1.45,1.75,2.45$, and 1 (a fixed chute without divergence) were designed and tested according to Table 1 and Figure 5. A constant chute bed slope of $2: 1$ was used in all the experiments. The number of blocks on the divergent models differed, given their different surface areas. Table 1 presents the detailed characteristics of the models.

Figure 6 demonstrates the laboratory models and arrangement of the chute components and sedimentary zone at downstream. Considering seven discharges for each model, a total of 63 experiments were conducted for all the models. The experiments were conducted at discharges of 3 , $5,6,9.5,15.5,17,20$, and $22 \mathrm{~L} / \mathrm{s}$.

3.3. Effect of Time on the Scour Hole Dimensions. An experiment was first conducted at a discharge of $22 \mathrm{~L} / \mathrm{s}$ under completely free conditions at downstream to obtain a quasiequilibrium scour hole. The temporal changes in the maximum scour depth were recorded. It was found that 80 and $95 \%$ of the maximum scour depth occurred after 35 and $120 \mathrm{~min}$, respectively. The experiment continued up to $240 \mathrm{~min}$, but the scour depth remained almost constant. On the other hand, according to the simulation of discharge from the main structure for $9 \mathrm{~h}$, the model was executed for $2 \mathrm{~h}$ considering the model scale. Given the time-scouring diagram, all the experiments and models were performed within $2 \mathrm{~h}$. These conditions are also acceptable to obtain a quasiequilibrium scour hole as the chute with baffle blocks dissipating a large portion of the flow energy. There are numerous studies on the effect of time on the scouring downstream of hydraulic structures. The experiments conducted by Oliveto [15] lasted for 1 to $3 \mathrm{~h}$ during which the main scour hole was formed. Herein, the effects of block type and shape were investigated as well as the sidewall angle of the structure by assuming other parameters constant. Similar test duration was considered for all the experiments in this study. Figure 7 shows the changes in the maximum scour depth with respect to time. After each experiment, a vehicle (chariot) moving along $x$ and $y$ axes with a laser meter was used to record the scour hole and point bar topographies, after which the collected data were analyzed.

For ensuring the accuracy of the data obtained from the laboratory model, the results obtained from the chute model without blocks were compared with those obtained from the relations presented in Table 2 by other studies, and their data are 


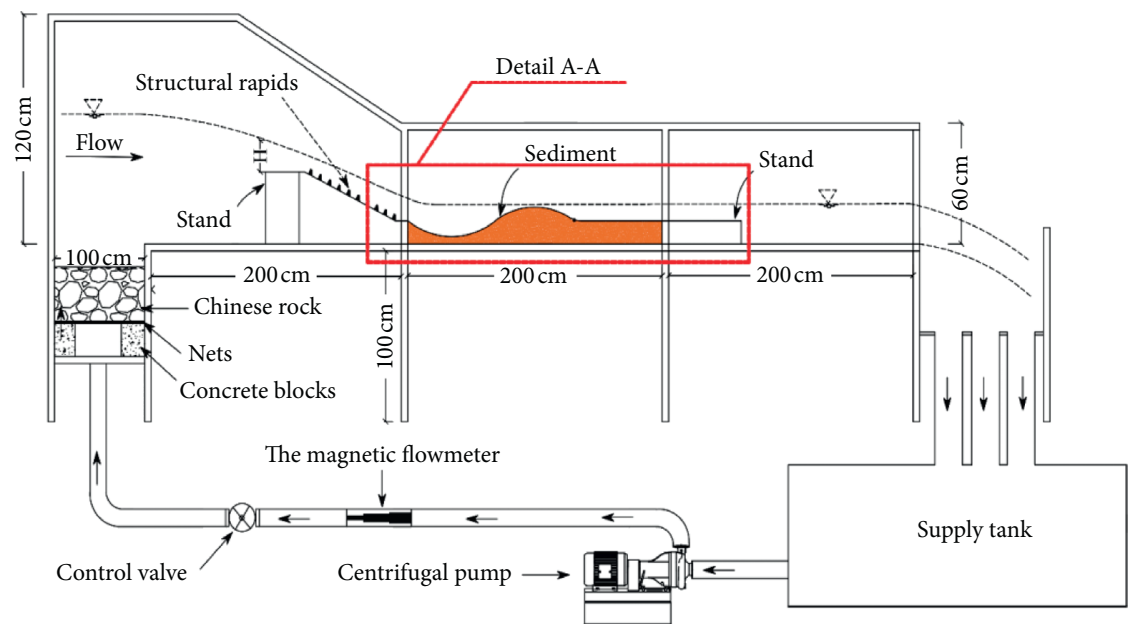

(a)

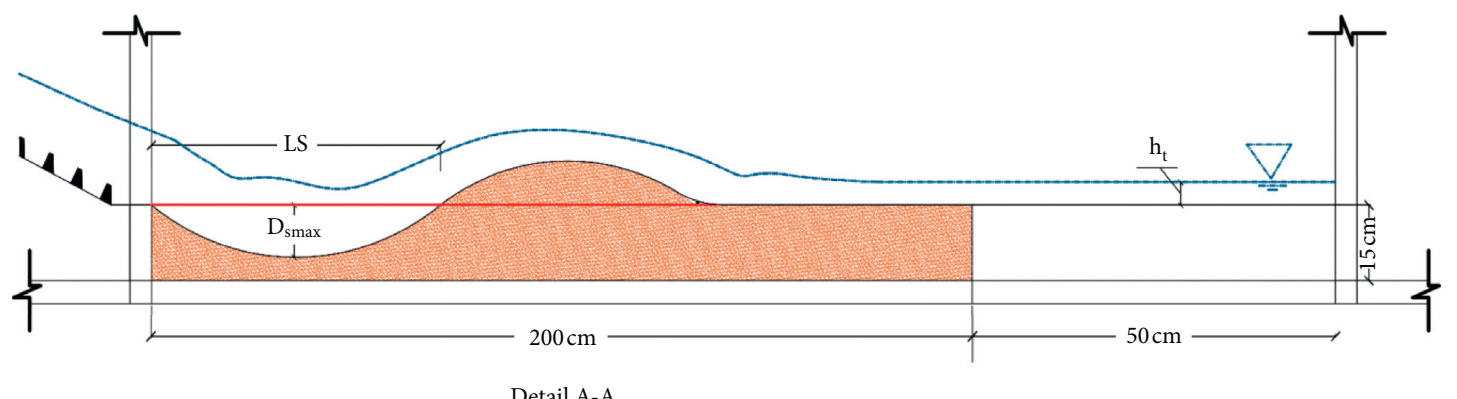

(b)

FIgURE 3: The detail of experimental flume and the place of installing the chute structure: (a) Longitudinal profile of the laboratory flume and equipment used with baffle block chute and (b) sediment bed downstream of the chute.

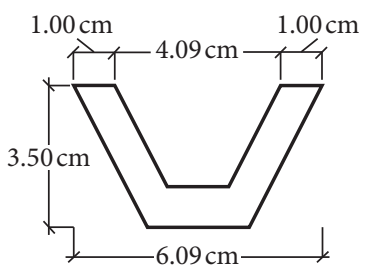

(a)

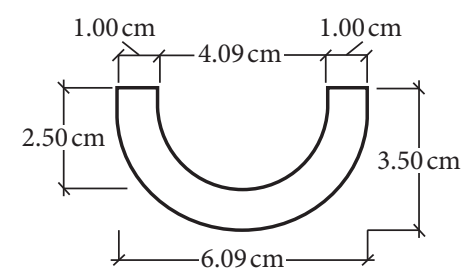

(b)
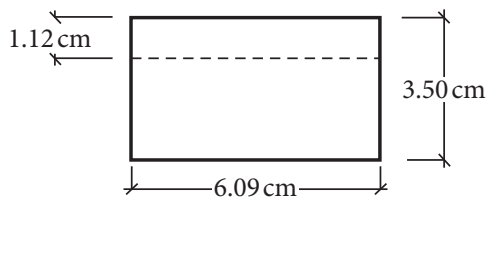

(c)

FIgURE 4: Top view of the plan and dimensions of the blocks: (a) trihedral, (b) semicircular, and (c) trapezoidal (USBR).

indicated in Figure 8. According to the results, $\left(\mathrm{D}_{\text {smax }} / \mathrm{H}\right)$ was elevated by increasing the $(\mathrm{yc} / \mathrm{H})$, suggesting that the maximum scour depth downstream of the chute increases by increasing the discharge rate. The results of this study are consistent especially with those obtained in a previous study [12].

Experiments were conducted at seven discharge rates from 3 to $22 \mathrm{~L} / \mathrm{s}$ on 9 different models with rigid blocks of different geometries with and without divergence. The results were presented as dimensionless figures. The scour hole depth and length, as well as energy dissipation, were also compared and discussed.

\section{Results and Discussion}

4.1. Bed Topography. The longitudinal profiles of the bed scour were plotted at different discharges and divergence ratios, as shown in Figures 9 and 10 using the data on scour and sedimentation downstream of the laboratory models. Figure 9 displays the longitudinal scour profiles at 6.5, 9.5, and $15.5 \mathrm{~L} / \mathrm{s}$ for three types of blocks without divergence. In all the cases, the standard blocks indicated the maximum scour depth along the flume centreline.

Figure 10 reveals the longitudinal scour profiles for semicircular blocks at different divergence ratios at 6.5, 9.5, and $15.5 \mathrm{~L} / \mathrm{s}$. As can be seen, the divergence causes an increase in the scour depth in the middle of the channel compared to the nondivergent model. However, the maximum scour depth was observed for DW1 divergence, where the scour rate was decreased by elevating the divergence ratio. Furthermore, an ordered scour hole was formed by raising the divergence ratio. Despite the formation of a set of holes in the nondivergent model, a single hole was formed as 
TABLE 1: Dimensions and characteristics of the models constructed on the chute tested in the laboratory.

\begin{tabular}{cccccccccc}
\hline $\begin{array}{c}\text { Model and block } \\
\text { geometry }\end{array}$ & $L(\mathrm{~cm})$ & $\begin{array}{c}M \\
(\mathrm{~cm})\end{array}$ & $\begin{array}{c}b 1 \\
(\mathrm{~cm})\end{array}$ & $\begin{array}{c}b 2=W \\
(\mathrm{~cm})\end{array}$ & $b 2 / b 1$ & $\begin{array}{c}\text { Number of the blocks } \\
\text { on the chute }\end{array}$ & $\begin{array}{c}\text { Chute bed } \\
\text { slope }\end{array}$ & $\begin{array}{c}\text { The number of experiments } \\
\text { for each model }\end{array}$ \\
\hline 1 & (CW-USB) & 103.15 & - & 97.5 & 97.5 & 1 & 80 & $2: 1$ & 7 \\
2 & (CW-SCB) & 103.15 & - & 97.5 & 97.5 & 1 & 80 & $2: 1$ & 7 \\
3 & (CW-TRB) & 103.15 & - & 97.5 & 97.5 & 1 & 80 & $2: 1$ & 7 \\
4 & (DW1-SCB) & 103.15 & 15.9 & 67.25 & 97.5 & 1.45 & 69 & 7 \\
5 & (DW1-TRB) & 103.15 & 15.9 & 67.25 & 97.5 & 1.45 & 69 & 7 \\
6 & (DW2-SCB) & 103.15 & 19.2 & 55.08 & 97.5 & 1.75 & 65 & 7 & 7 \\
7 & (DW2-TRB) & 103.15 & 19.2 & 55.08 & 97.5 & 1.75 & 65 & $2: 1$ & 7 \\
8 & (DW3-SCB) & 103.15 & 28.43 & 39.80 & 97.5 & 2.45 & 58 & $2: 1$ & 7 \\
9 & (DW3-TRB) & 103.15 & 28.43 & 39.80 & 97.5 & 2.45 & 58 & $2: 1$ & 7 \\
\hline
\end{tabular}

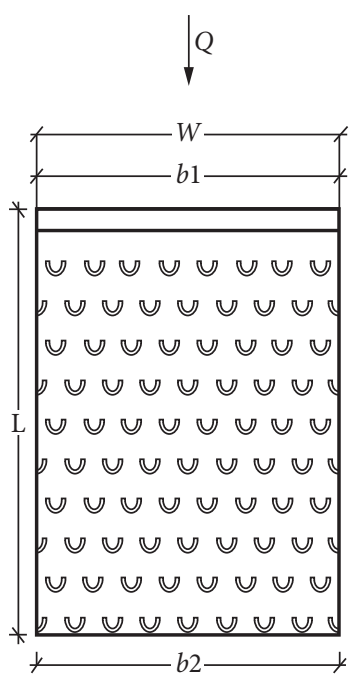

(a)

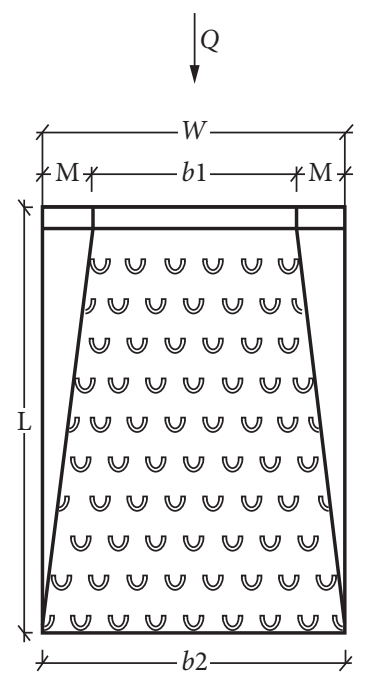

(b)

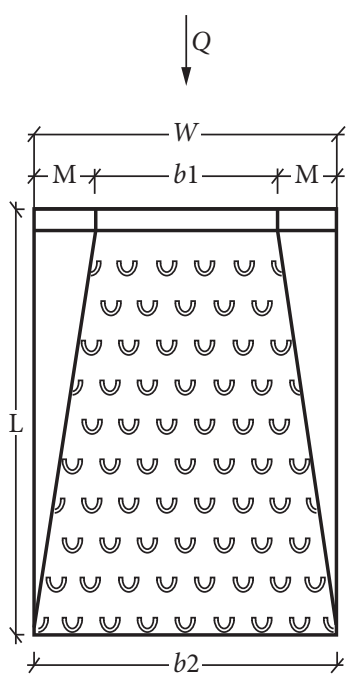

(c)

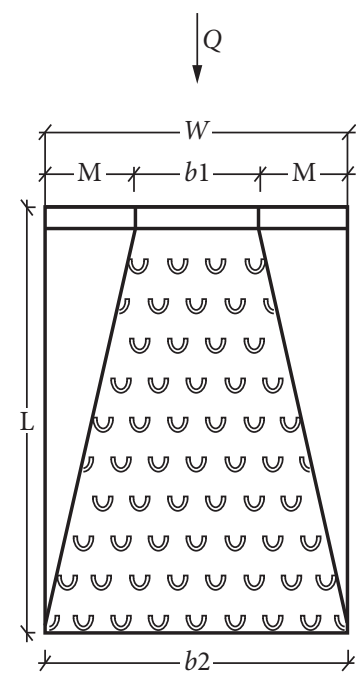

(d)

Figure 5: The plan and dimensions of the chute with different opening ratios and semicircular blocks: (a) $b 2 / b 1=1$, (b) $b 2 / b 1=1.45$, (c) $b 2 /$ $b 1=1.75$, and (d) $b 2 / b 1=2.45$.

the divergence ratio increased. A deeper scour hole was formed at $6.5 \mathrm{~L} / \mathrm{s}$ compared to $9.5 \mathrm{~L} / \mathrm{s}$, with the increase in the divergence ratio $(b 2 / b 1)$ up to 2.45 .

Figures 11 and 12 reveal the topography of the scour hole downstream of the chute at a discharge rate of $15.5 \mathrm{~L} / \mathrm{s}$. According to the results obtained regarding the bed topography, an asymmetric scour hole was formed along the channel width with a maximum depth on both sides of the channel centreline. The topography of the scour hole for the chute with semicircular blocks at different divergence ratios suggested that unlike the nondivergent model, the maximum scour hole occurred in the vicinity of the walls as the divergence ratio increased. Besides, with an increase in the divergence ratio, the point bars started to approach the walls, presumably due to the formation of secondary flows colliding with the walls, causing the scour and transporting the scour-induced sediments downstream of the side walls.

Figure 12 shows the topography of the eroded beds for the nondivergent chutes with various block geometries. As can be seen, in the case where a standard block was used, the maximum scour hole length occurred in the middle of the channel and a large point bar was formed downstream of the scour hole in the middle of the channel. However, when semicircular and trihedral blocks were employed rather than the USBR standard block, the scour hole was extended on both sides tangential to the side walls. The scour hole was further extended downstream of the chute towards the channel centreline. Despite a decrease in the depth and length of the scour hole at its centre using the proposed blocks, the scour rate was significantly increased at wall sides, leading to the heightened hole length.

Clearly, the divergence ratio of the chute influences the rate and distribution of scour downstream of this structure. An asymmetric bed topography was observed due to transverse fluctuations of the flow in the constant width chute. However, a relatively symmetric scour pattern was seen for the models with a divergence ratio of larger than one. With the elevation of the divergence ratio, the maximum scour hole was approached from the middle of the channel towards the side walls. Moreover, the sedimentation pattern downstream of the scour hole was influenced by the chute divergence ratio and the Froude number upstream of the flow, where the most uniform scour and sedimentation pattern with the minimum depth of the scour hole was 


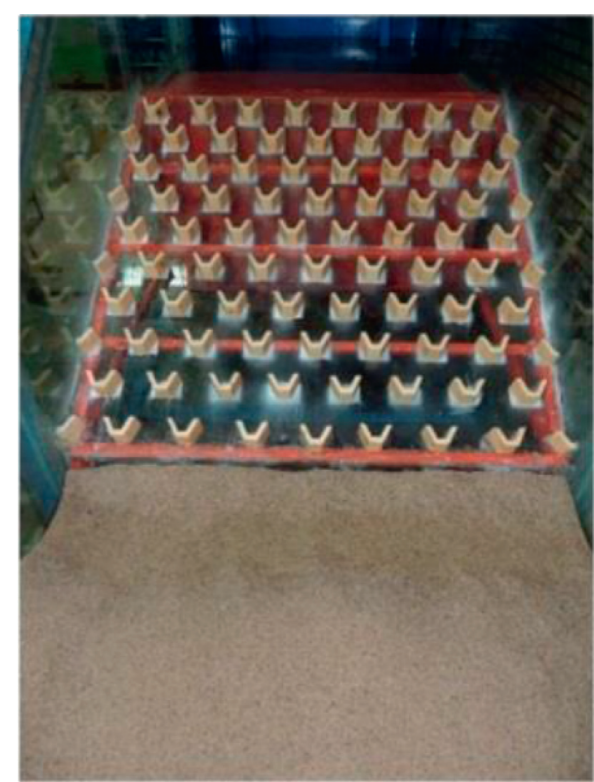

(a)

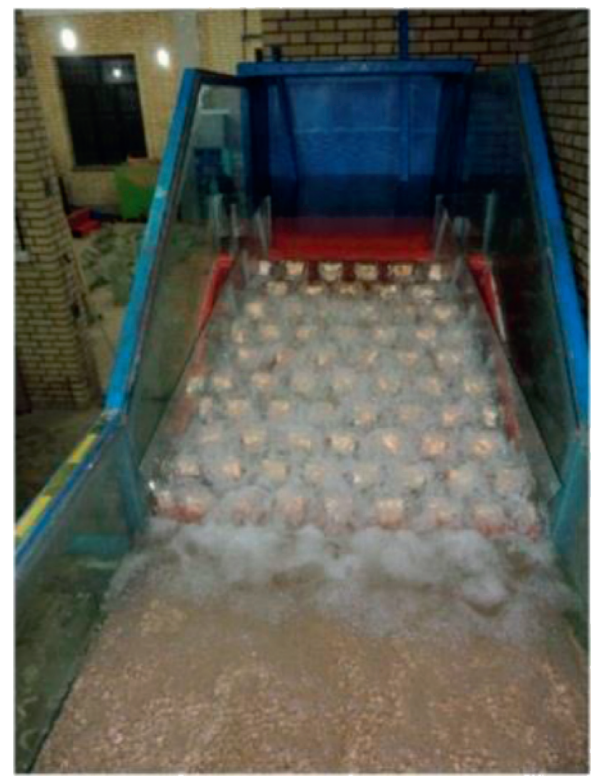

(c)

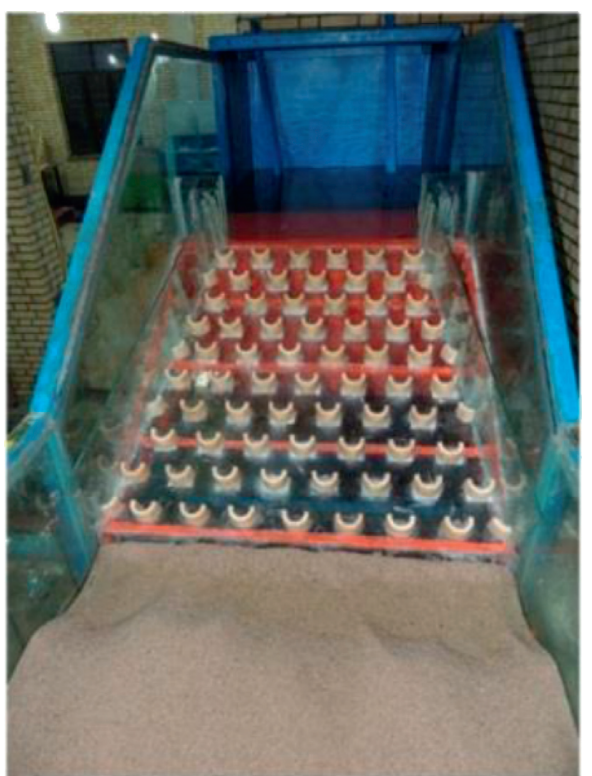

(b)

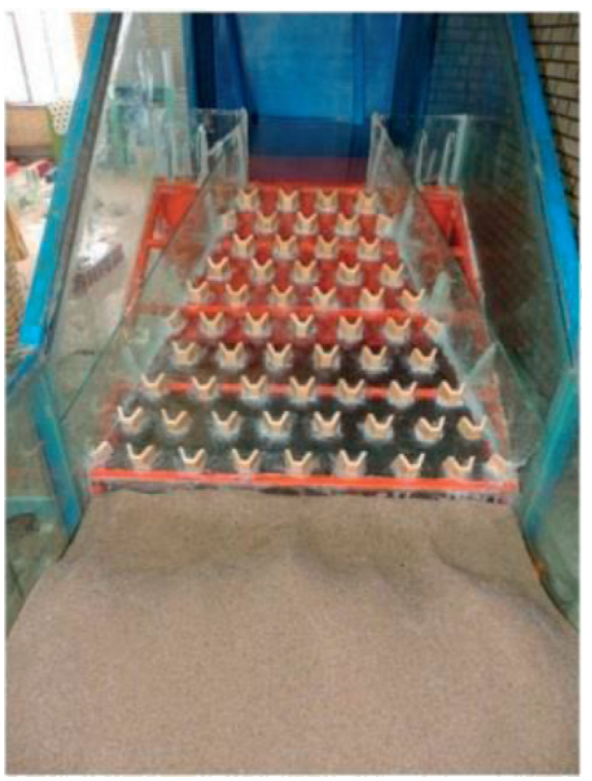

(d)

FIgURE 6: The baffled chute: (a) $b 1 / b 2=1$ with a trihedral block, (b) $b 1 / b 2=1.45$ with a semicircular block, (c) $b 1 / b 2=1.75$ with a USBR block, and (d) $b 1 / b 2=2.45$ with a trihedral block.

observed for DW2. Hence, it can be concluded that the uniformity of the scour distribution and sedimentation downstream of the structure was increased to a large extent by increasing the divergence ratio from 1 to 1.75 at a constant discharge rate of $9.5 \mathrm{~L} / \mathrm{s}$. However, with a further increase in the divergence ratio to 2.45 , as the Froude number and consequently the surface flow velocity was increased and caused the overturbulence, a nonuniform scour pattern was again formed, leading to an increase in the maximum scour hole and point bar height. The effect of various parameters influencing the scour hole is discussed in the following sections.
4.2. The Mean and Maximum Depth of the Scour Hole. Figure 13 reveals the changes in the mean and maximum depths of the scour hole at different divergence ratios for different block geometries at various Froude numbers upstream of the chute. Figure 13(a) indicates the relationship between the changes in the dimensionless mean depth of the scour hole at different Froude numbers for the flow over the chute. Clearly, the maximum mean depth of the scour hole was observed for the standard blocks without inlet divergence. The mean and maximum depths of the scour hole were significantly diminished by up to 50 and $40 \%$, respectively, by increasing $(b 2 / b 1)$ from 1 to 2.45 and changing 


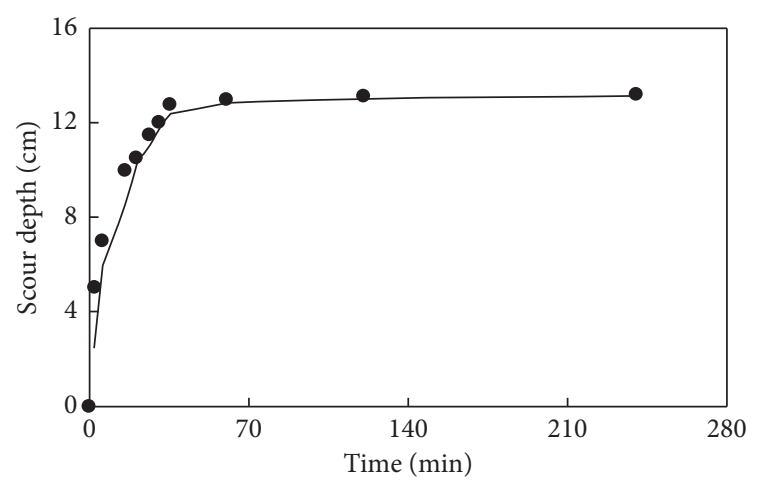

- Time depended scouring

FIgURE 7: The changes in the scour depth with time.

TABLE 2: Relations for determining the scour depth downstream of hydraulic structures [14].

\begin{tabular}{lcc}
\hline Source & Year & Proposed equation \\
\hline$[19]$ & 1932 & $d_{s}+y_{t}=\left(c_{s} q^{0.57} H^{0.2} / d_{90}^{0.32}\right)$ \\
{$[20]$} & 1961 & $d_{s}=0.55\left(6 H^{0.25} q^{0.5}\left(y_{t} / d 90\right)^{1 / 3}-y_{t}\right)$ \\
{$[21]$} & 1967 & $d_{s}=0.78\left(y_{t}^{0.35} q^{0.7} / d_{90}^{0.4}\right)$ \\
\hline
\end{tabular}

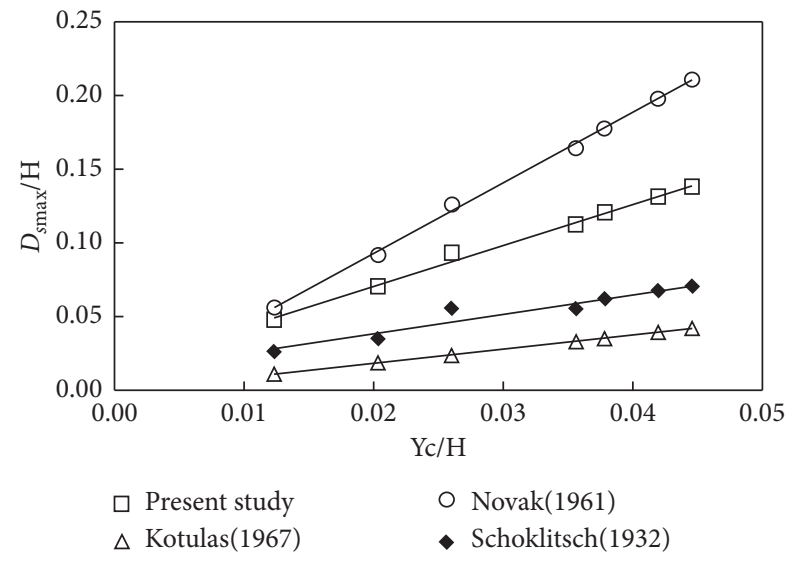

Figure 8: The relationship between dimensionless critical depth and maximum scour depth obtained in this study and comparing the results with those obtained in the literature.

the block geometry from standard to semicircular and trihedral blocks, as a result of the increased Froude number.

At a constant Froude number upstream of the chute, the maximum and minimum mean scour depths were observed for the model without divergence and with standard blocks, respectively, and also with a divergence ratio of 2.45 and semicircular blocks. The effect of block geometry on structure performance was also investigated. According to the results, at all divergence ratios and the cases with no divergence, except for $(b 2 / b 1=1.75)$, the semicircular block outperformed other geometries in terms of reducing the mean depth of the scour hole depth, in particular at Froude numbers less than 0.25 .

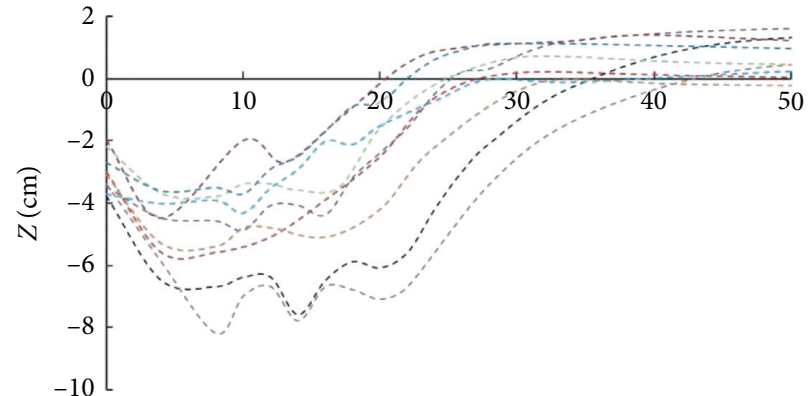

$$
\begin{aligned}
& X(\mathrm{~cm})
\end{aligned}
$$

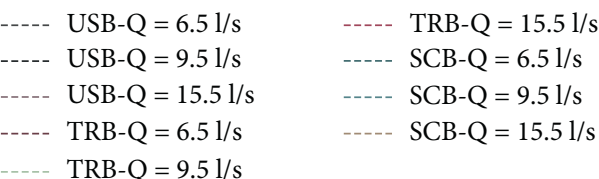

Figure 9: Comparison of the longitudinal scour profiles at three discharges and an opening ratio of 1 for three block geometries.

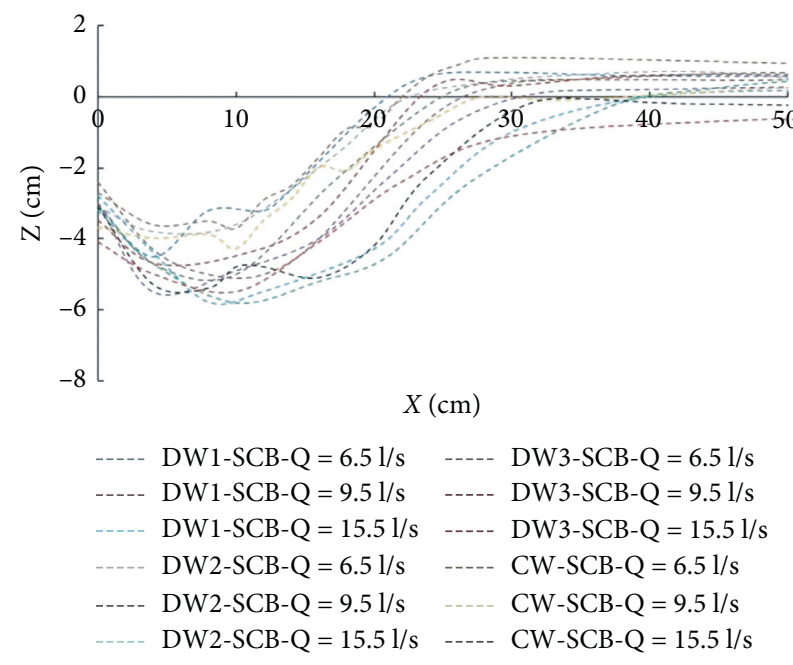

FIgURE 10: Comparison of the longitudinal scour profiles at three discharges and opening ratios for a semicircular block.

Figure 13(b) indicates the maximum depth of the scour hole for various models at different upstream Froude numbers. In general, with the increase in the Froude number, the maximum depth of the scour hole was increased for all the blocks at all divergence ratios, but at different rates for different models. At a constant Froude number, the maximum scour hole depth was observed for the nondivergent model $(b 2 / b 1=1)$ with standard blocks, while the minimum scour depth was found for the model with a divergence ratio $(b 2 / b 1)$ of 2.45 with semicircular blocks. It can be concluded that despite the divergence at chute inlet, semicircular blocks may cause a significant reduction in the maximum and mean depths of the scour hole in comparison with the trihedral and standard USBR blocks. This can be related to the semicircular geometry of the blocks influencing the energy dissipation of the flow through the 

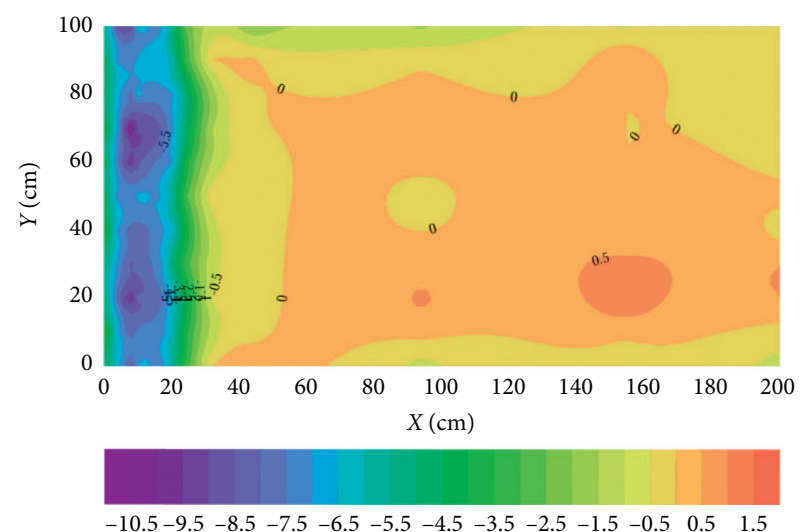

(a)

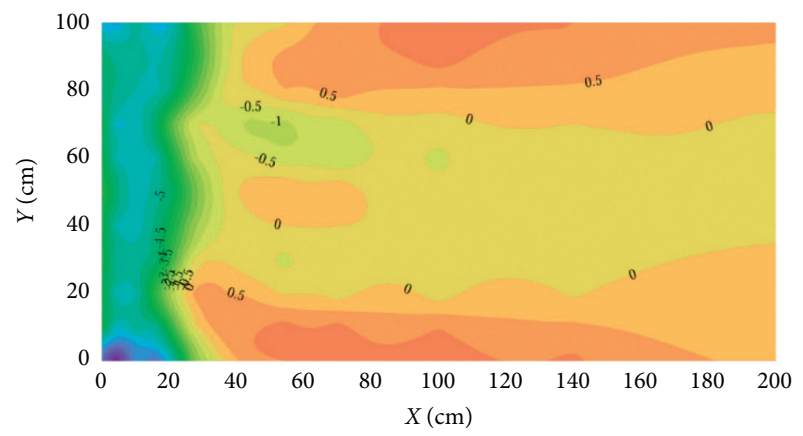

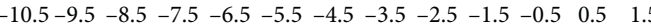

(c)
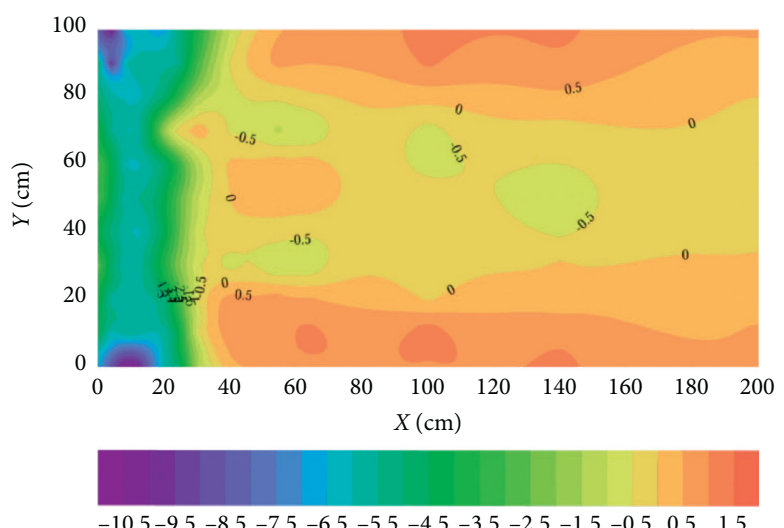

(b)
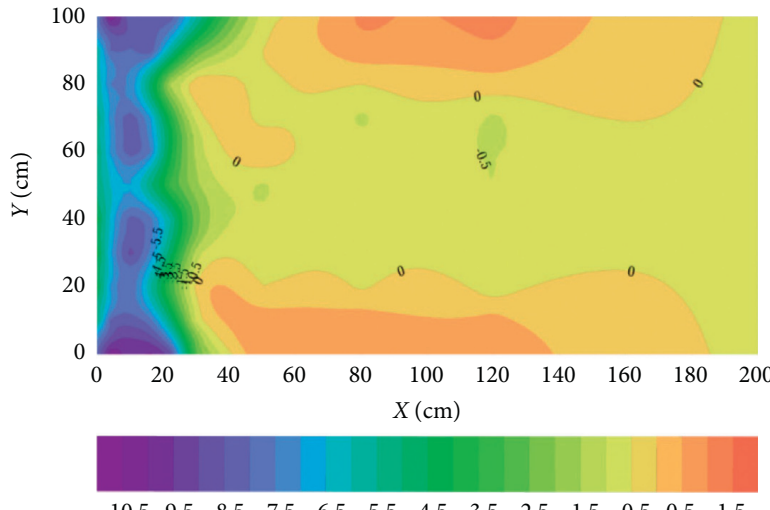

(d)

Figure 11: The bed topography for a chute with a semicircular block at a discharge of $15.5 \mathrm{~L} / \mathrm{s}$ and different divergence ratios of (a) 1 , (b) 1.45 , (c) 1.75 , and (d) 2.45 .

blocks to reduce the mean and maximum lengths of the scour hole.

4.3. The Mean and Maximum Lengths of the Scour Hole. Figures 14(a) and 14(b) represent the changes in the mean and maximum lengths of the scour hole, respectively, at various divergence ratios for different block types at different Froude numbers upstream of the chute under various conditions. As can be clearly seen, with the increase in the Froude number upstream of the chute, the mean and maximum lengths of the scour hole were elevated in all the models.

As shown in Figure 14(a), the dimensionless ratio $(L s m e a n / H)$ related to the average length of scour increases in all the lengths except for the model with the constant width and USBR blocks by increasing the Froude number. As demonstrated in Figure 14(b), the dimensionless ratio $(L s m a x / H)$ increases too by increasing the Froude number. Even in the conventional model with the constant width and USBR blocks, the $(L s \max / H)$ was higher than other models. Also, the model with the divergent walls and trihedral blocks (DWS-TRB) had the least ratio.

Furthermore, with the increase in the opening ratio (b2/ b1) from 1 to 2.45 , the maximum and mean lengths of the scour hole were decreased from 45 to $60 \%$ and from 30 to $70 \%$ at Froude numbers of 0.1 and 0.3 , respectively. A comparison of the performance of semicircular and trihedral blocks suggested that at each divergence ratio, the trihedral blocks reduced the scour hole length by $40 \%$ more than the semicircular blocks.

In general, it can be concluded that semicircular blocks outperform the standard and trihedral blocks in terms of reducing the maximum and mean depths of the scour hole. However, trihedral blocks outperformed the other block geometries concerning the reduction of the length of the scour hole.

\section{Energy Dissipation}

Figure 15 shows the relative energy dissipation of the flow passing over the chute at different Froude numbers upstream of the chute. As can be seen, the relative energy dissipation declined with the increase in the Froude number, but with different downtrends in different models.

Generally speaking, the models with semicircular blocks showed a higher relative energy dissipation at an identical opening ratio. The maximum energy dissipation was observed for the model with a semicircular block with a divergence ratio $(b 2 / b 1)$ of 2.45 (DW3-SCb). On the other 

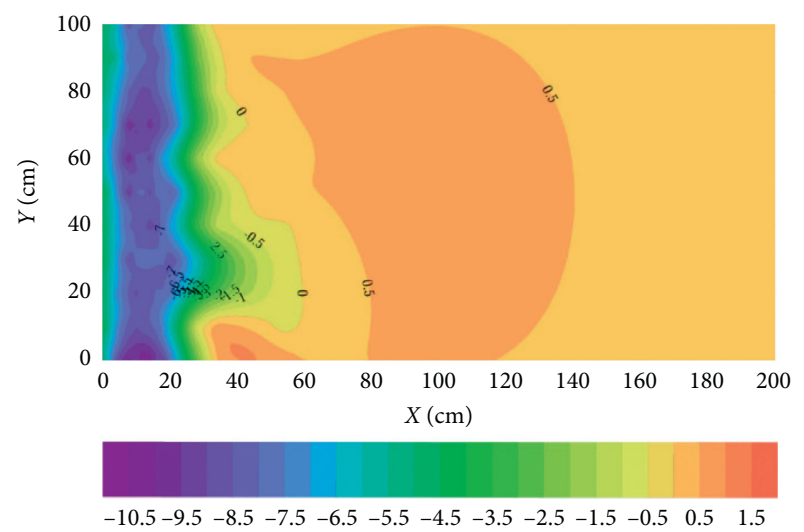

(a)
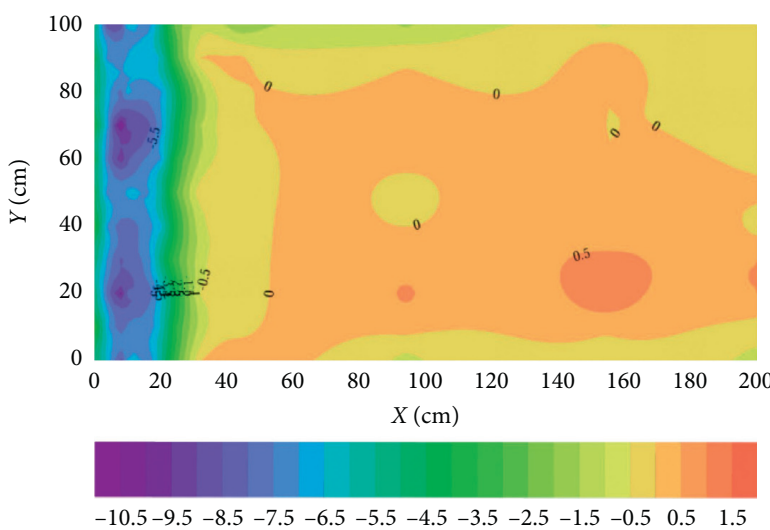

(b)
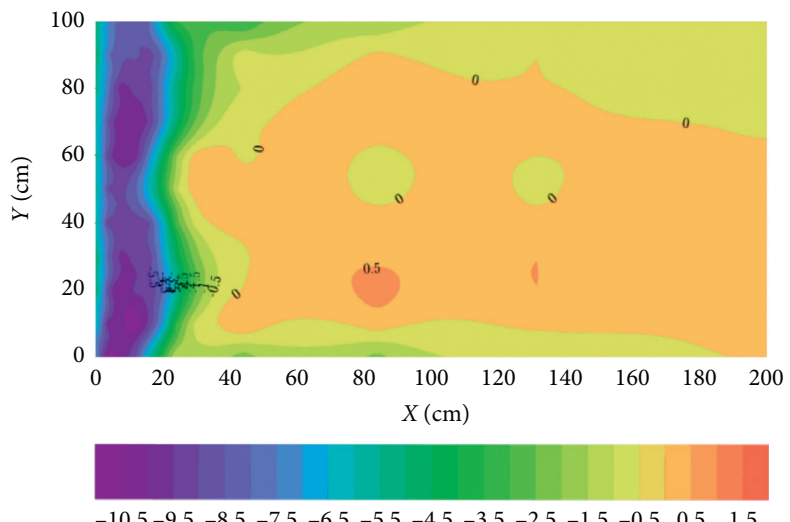

(c)

FIgURE 12: The bed topography of the chute without divergence at a discharge rate of $15.5 \mathrm{~L} / \mathrm{s}$ for (a) standard, (b) semicircular, and (c) trihedral blocks.

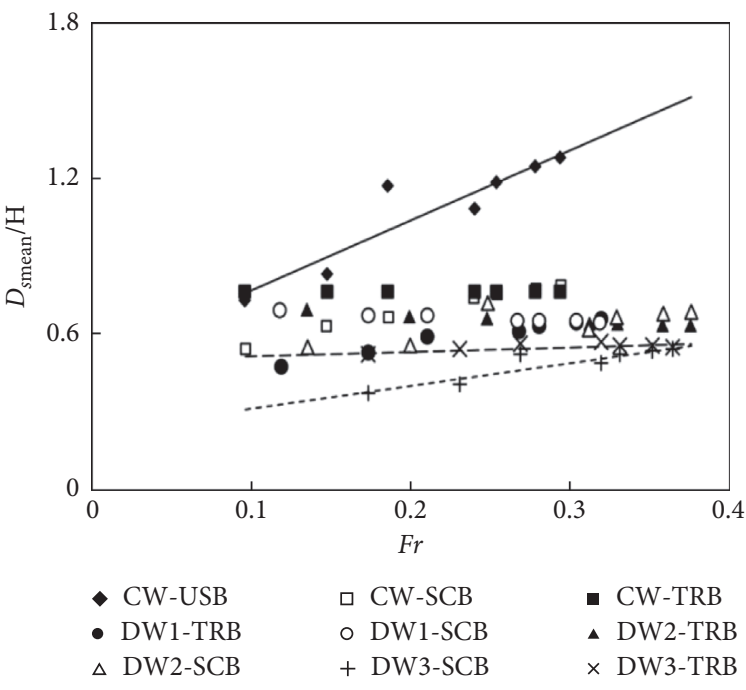

(a)

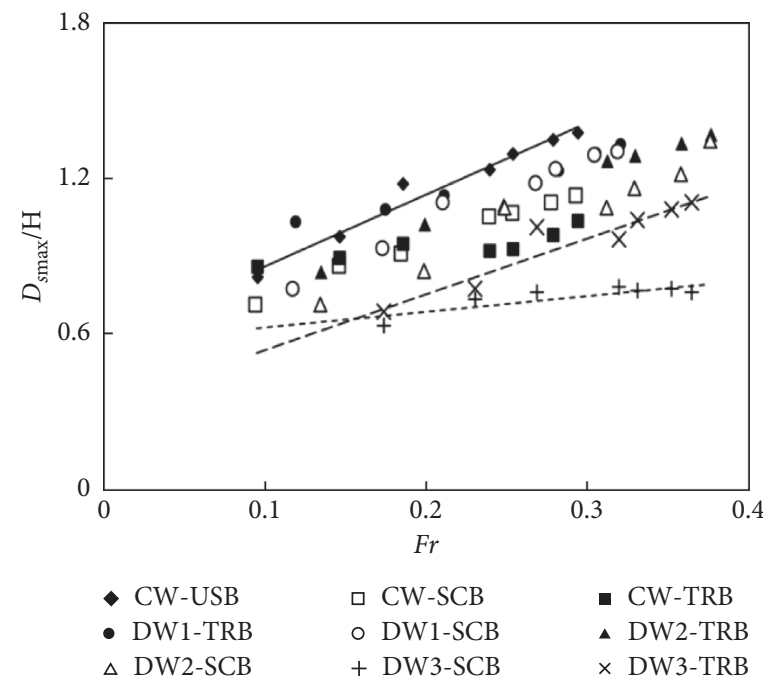

(b)

Figure 13: The changes in the dimensionless ratio with the Froude number: (a) mean depth of the scour hole; (b) maximum depth of the scour hole. 


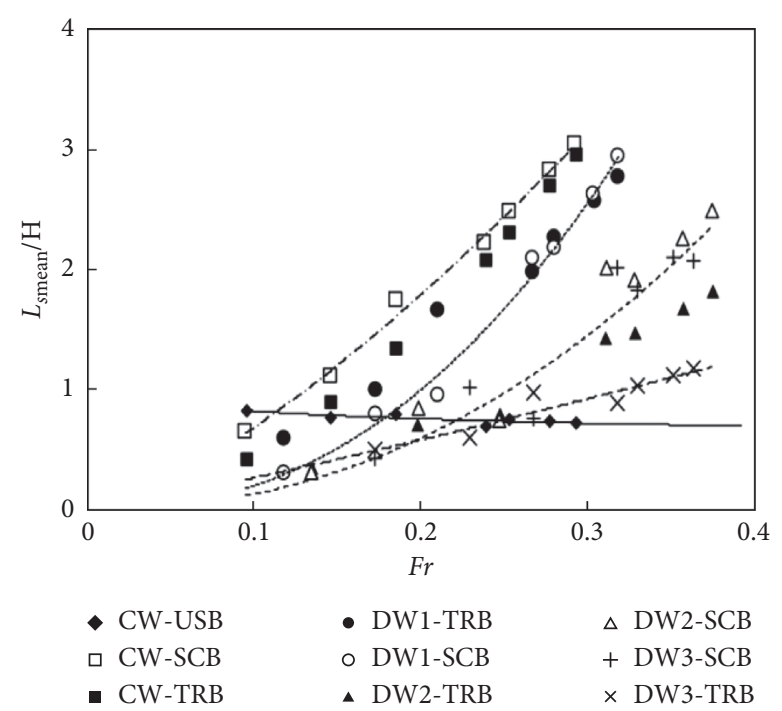

(a)

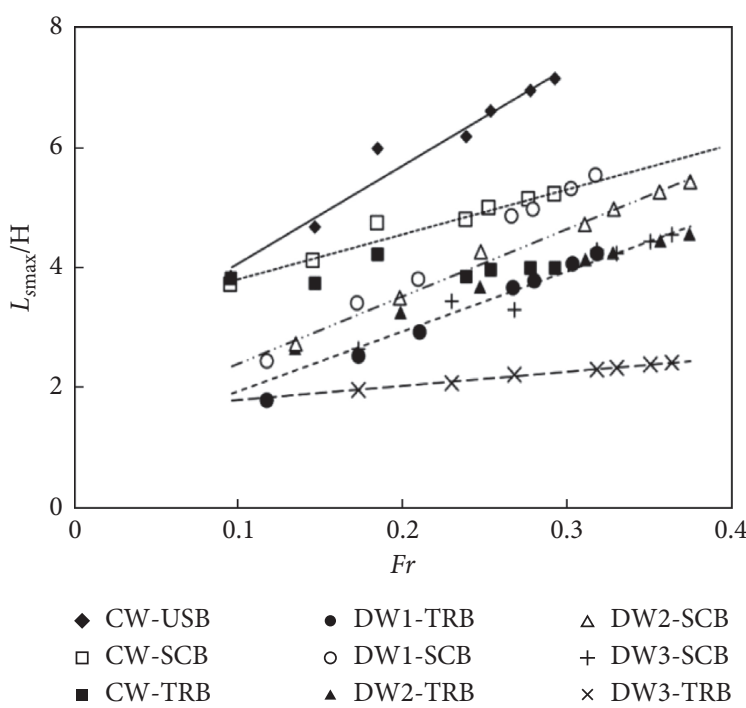

(b)

FIgURE 14: The changes in the dimensionless ratio with the Froude number: (a) the mean and (b) maximum lengths of the scour hole.

hand, the model with standard blocks without divergence (CW-USB) showed the minimum energy dissipation. Thus, it can be concluded that the flow energy drops downstream of the chute, leading to a decrease in the dimensions of the scour hole by changing the block geometries from standard to semicircular blocks and the subsequent increase in the turbulence and energy dissipation. The DW3-SCB and DW3-TRB models showed the maximum energy dissipation with the minimum length and depth of the scour hole. According to the results concerning the effect of divergence ratio on the relative energy dissipation, with the increase in the divergence ratio from 1 to 2.45 , the relative energy dissipation by the flow over the chute was increased from 4 to $8 \%$, presumably due to the flow acceleration upstream of the chute in response to the inlet divergence and the subsequent increase in the turbulence resulting from the collision of the flow with the middle blocks. This can ultimately lead to increased energy dissipation, thereby forming smaller scour holes.

5.1. Effect of the Model Scale. Air-water two-phase flows have been observed in several hydraulic structures, such as hydraulic jumps, intakes, drop-shafts, spillways, jets, and plunge pools. The flow phenomena are challenging in these structures, and yet relevant to the hydraulic design. Physical model testing is often applied to investigate related flow characteristics. The Froude similitude and scale factors larger than $30: 1$ are often applied in order to keep the physical models within economic dimensions and to minimize the discharges to supply. These small models characteristically underestimate the air entrainment and transport in the fluid since the effects of surface tension and viscosity are relatively overrepresented in the model; thus, water is used as the fluid in both model and prototype.
The model was simulated in the laboratory based on the Froude similarity simulation. Considering a 1:20 scale, the hydraulic conditions of the flow in the experimental model are shown in Table 3 using the correlations in the Froude similarity simulation.

Pfister and Chanson [16] conducted two basic studies on the Froude similarity simulation for a reasonable approximation of the inlet air flow. A $1: 10$ scale model was used in the first study. In the second study, information on the effects of the Weber and Reynolds numbers and acceptable ranges of these dimensionless numbers was used based on the experimental, field, or original data.

According to Pinto [22], the scale effect in the models simulated based on the Froude number is negligible in the case of minimum Weber and Reynolds numbers. They compared the models of different scales with the original model. Then, they discussed some studies and limitations in the literature. It is noteworthy that the limitations may be different depending on the flow conditions and aim of the modeling.

(i) According to the preliminary studies conducted by Chen, Pinto [22] believed that a critical Weber number of 30 should be considered, a Weber number greater than this critical value should be used to reduce the scale effect.

(ii) Lemos and Ramos [23] studied the results of a model simulated based on the Froude number with different scales. According to their results, for a 1 : 20 scale model and the Weber number above 36.5, the effect of surface tension can be ignored.

(iii) Consistent with the results of the study by Toombes and Chanson [24], Pfister and Hager [25] concluded that the Weber and Reynolds numbers should be in the ranges of $109<\mathrm{We}<234$ and 
TABLE 3: Model simulation in the laboratory based on the Froude similarity simulation.

\begin{tabular}{lcccc}
\hline Scale & Geometry & Velocity & Time & Discharge \\
\hline Equation & $L_{R}=\left(L_{m} / L_{p}\right)=(1 / 20)$ & $V_{R}=V_{m} / V_{p}=L_{R}^{1 / 2}$ & $t_{R}=t_{m} / t_{p}=L_{R}^{1 / 2}$ & $Q_{R}=\left(Q_{m} / Q_{p}\right)=L_{R}^{5 / 2}$ \\
Prototype & $H_{p}=0.90 \mathrm{~m}$ & $V_{p}=2.4 \mathrm{~m} / \mathrm{s}$ & $t_{p}=9 \mathrm{~h}$ & $Q_{p}=28 \mathrm{~m}^{3} / \mathrm{s}$ \\
Model & $H_{m}=4.5 \mathrm{~cm}$ & $V_{m}=0.54 \mathrm{~m} / \mathrm{s}$ & $t_{m}=2 \mathrm{~h}$ & $Q_{m}=15.5 \mathrm{~L} / \mathrm{s}$ \\
\hline
\end{tabular}

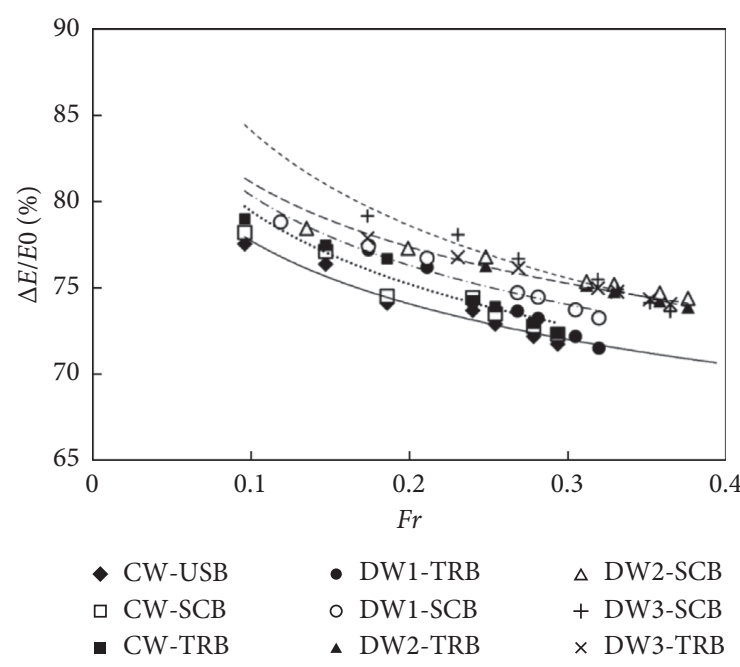

FIGURE 15: Relative energy dissipation at different Froude numbers upstream of the chute.

TABLE 4: Froude similarity modeling and calculated Reynolds, Weber, and Froude numbers.

\begin{tabular}{lccccc}
\hline$Q(\mathrm{~L} / \mathrm{s})$ & $y_{0}(\mathrm{~cm})$ & $\mathrm{Fr}_{0}$ & $\mathrm{Fr}_{\mathrm{d}}$ densimetric & $R_{e} \times 10^{5}$ & $\mathrm{We}$ \\
\hline 3.00 & 4.68 & 0.095 & 0.76 & 1.56 & 67.02 \\
6.50 & 5.90 & 0.145 & 1.17 & 2.37 & 127.13 \\
9.50 & 6.50 & 0.183 & 1.14 & 2.96 & 180.21 \\
15.50 & 7.60 & 0.236 & 1.71 & 4.08 & 292.21 \\
17.00 & 7.78 & 0.250 & 1.69 & 4.31 & 318.37 \\
20.00 & 8.16 & 0.274 & 1.82 & 4.77 & 372.34 \\
22.00 & 8.39 & 0.289 & 1.90 & 5.68 & 408.11 \\
\hline
\end{tabular}

$1.7 \times 105<\operatorname{Re}<5.2 \times 105$, respectively, to minimize the scale effect.

(iv) Borja et al. [26] studied the energy dissipation in a 1 : 100 scale flip bucket spillway and found the significant effect of the surface tension at $\mathrm{We}<53$.

According to Felder and Chanson [27], hydraulic phenomena show different behaviors, and the scale effect may pose different limitations depending on the research objectives. Bollaert [28] suggested different simulation rules for various fluid phases.

A 1:20 scale model was selected in this study considering the experimental limitations to provide the required discharges. The required data were collected and used in the calculations. Dimensionless numbers were calculated. Based on the Froude similarity modeling, the Reynolds, Weber, and Froude numbers were calculated at different discharges from the following relations, and the results are presented in Table 4 .
The results showed that the Weber number ranged from 67.02 to 408.11. According to the range mentioned in the literature for the Weber number, the scale effect was negligible for the chute with baffle blocks. According to Novak [20] recommendations, the effect of surface tension is insignificant when the head is larger than $5 \mathrm{~cm}$. Considering the Reynolds number range in the above table, the scale effect is perhaps insignificant, and the effect of viscous forces can be therefore ignored. According to the above recommendations and limitations, a 1:20 scale model seems to be suitable in this study. However, a $1: 10$ scale model is recommended to be used for studying the two-phase water-air flows.

\section{Conclusion}

In this study, the effects of different divergence ratios of a baffled chute and block geometries installed on the chute were investigated on the pattern and dimensions of the scour hole downstream of the chute. For this purpose, semicircular and trihedral blocks were proposed as alternatives to the standard USBR blocks and then, the effect of blocks of different geometries on the scour downstream of the chute was investigated. The effect of three divergence ratios $(b 2 / b 1)$ of $1,1.45$, and 2.45 at chute inlet was also studied. According to the results, with the increase in the inlet divergence ratio for all the block geometries, the scour hole and point bars showed a greater asymmetry and more uniform topography relative to the flume centreline. An increase in the divergence ratio from 1 to 2.45 caused a significant reduction in the mean and maximum depths of the scour hole. The use of standard USBR blocks at a constant chute width led to the maximum depth of the scour hole in the middle of the channel. However, the proposed semicircular and trihedral blocks shifted the maximum scour depth towards the side walls. This can be related to the geometry of the blocks forming the secondary eddy currents due to the wall curvature. The collision of the eddy currents with the side walls and the subsequent formation of horseshoe-shaped vortices result in scouring of the side walls in addition to extending the hole on both sides of the channel in the vicinity of the side walls. This may endanger the wall stability and should be further studied. A comparison of the results with those reported in the literature indicated that as the geometry changed from standard USBR to semicircular blocks, the mean depth of the scour hole was decreased by $50 \%$. According to the results obtained regarding the effect of the inlet divergence ratio, the divergence caused the formation of more asymmetric scour holes with a lower length and depth. Finally, as the divergence ratio was increased from 1 to 2.45 , energy dissipation was elevated by $8 \%$ due to a reduction in the scour hole dimensions. According to the range mentioned in the literature for the Weber number, the 
scale effect was negligible for the chute with baffle blocks. Considering the Reynolds number range calculated in the results, the scale effect is perhaps insignificant, and the effect of viscous forces can be therefore ignored. According to the recommendations and limitations, a 1:20 scale model seemed to be suitable in this study. However, a $1: 10$ scale model is recommended to be used for studying the twophase water-air flows.

\section{Abbreviations}

$L_{s}$ : $\quad$ Scour hole length

$\mathrm{D}_{\text {smax }}$ : Maximum scour depth

$\mathrm{D}_{\text {smean }}$ : Mean scour depth

$V_{s}$ : Scour hole volume

hb: Block height

$b 1$ : Spillway width upstream of the inlet

b2: $\quad$ Spillway width downstream of the chute

W: Spillway width downstream of the chute

yc: Critical depth of flow over the spillway

$H$ : $\quad$ Head upstream of spillway in the reservoir

$X: \quad$ Total length of the sedimentary bed

$Y$ : $\quad$ Total width of the sedimentary bed

$M$ : $\quad$ Length of convergence at upstream

L: $\quad$ Length of chute

Q: $\quad$ Flow discharge

$F_{r}$ : $\quad$ Froude number of the flow upstream of the spillway

$\triangle E / E$ : Energy dissipation

USB: USBR block

SCB: Semicircle block

TRB: Trihedral block

CW: Constant width

DW: Diverging width

Ht: $\quad$ Tail water

$R_{\mathrm{e}}: \quad$ Reynolds number

$W_{\mathrm{e}}$ : Weber number

$\mathrm{Fr}_{0}$ : $\quad$ Froude number

$\mathrm{Fr}_{\mathrm{d}}$ : densimetric Froude number

$\mathrm{g}^{\prime}$ : $\quad$ Modified gravitational acceleration.

\section{Data Availability}

The experimental data used to support the findings of this study are included within the article.

\section{Conflicts of Interest}

The authors declare that there are no conflicts of interest regarding the publication of this paper.

\section{References}

[1] N. E. Bormann and P. Y. Julien, "Scour downstream of gradecontrol structures," Journal of Hydraulic Engineering, vol. 117, no. 5, pp. 579-594, 1991.

[2] J. Farhoudi and K. V. Smith, "Local scour profiles downstream of hydraulic jump," Journal of Hydraulic Research, vol. 23, no. 4, pp. 343-358, 1985.

[3] H. K. Zare and J. C. Doering, "Energy dissipation and flow characteristics of baffles and sills on stepped spillways,"
Journal of Hydraulic Research, vol. 50, no. 2, pp. 192-199, 2012.

[4] V. D'Agostino and V. Ferro, "Scour on alluvial bed downstream of grade-control structures," Journal of Hydraulic Engineering, vol. 130, no. 1, pp. 24-37, 2004.

[5] B. Dargahi, "Scour development downstream of a spillway," Journal of Hydraulic Research, vol. 41, no. 4, pp. 417-426, 2003.

[6] S. Pagliara and M. Palermo, "Influence of tailwater depth and pile position on scour downstream of block ramps," Journal of Irrigation and Drainage Engineering, vol. 136, no. 2, pp. 120-130, 2009.

[7] S. Pagliara and M. Palermo, "Effect of stilling basin geometry on clear water scour morphology downstream of a block ramp," Journal of Irrigation and Drainage Engineering, vol. 137, no. 9, pp. 593-601, 2010.

[8] A. Peterka, Hydraulic Design of Stilling Basins and Energy Dissipators, Engineering Monograph No. 25, U. S. Department of Interior, Bureau of Reclamation, Socorro, NM, USA, 1964.

[9] H. Chanson and L. Toombes, "Energy dissipation and air entrainment in stepped storm waterway: Experimental study," Journal of Irrigation and Drainage Engineering, vol. 128, no. 5, pp. 305-315, 2002.

[10] N. Kaya and M. E. Emiroglu, "Study of oxygen transfer efficiency at baffled chutes," Proceedings of the Institution of Civil EngineersWater Management, vol. 163, no. 9, pp. 447-456, 2010.

[11] M. Tuna, "Effect of offtake channel base angle of stepped spillway on scour hole," Iranian Journal of Science and Technology, Transactions of Civil Engineering, vol. 36, no. C2, p. 239, 2012.

[12] E. Elnikhely, "Investigation and analysis of scour downstream of a spillway," Ain Shams Engineering Journal, vol. 9, no. 4, pp. 2275-2282, 2017.

[13] G. Oliveto and V. Comuniello, "Local scour downstream of positive-step stilling basins," Journal of Hydraulic Engineering, vol. 135, no. 10, p. 846, 2009.

[14] M. C. Tuna and M. E. Emiroglu, "Effect of step geometry on local scour downstream of stepped chutes," Arabian Journal for Science and Engineering, vol. 38, no. 3, pp. 579-588, 2013.

[15] G. Oliveto, "Local scouring downstream of a spillway with an apron," Proceedings of the Institution of Civil Engineers Water Management, vol. 166, no. 5, pp. 254-261, 2013.

[16] M. Pfister and H. Chanson, "Two-phase air-water flows: Scale effects in physical modeling," Journal of Hydrodynamics, vol. 26, no. 2, pp. 291-298, 2014.

[17] B. W. Melville, "Local scour at bridge abutments," Journal of Hydraulic Engineering, vol. 118, no. 4, pp. 615-631, 1992.

[18] A. J. Raudkivi and R. Ettema, "Clear-water scour at cylindrical piers," Journal of Hydraulic Engineering, vol. 109, no. 3, pp. 339-350, 1983.

[19] A. Schoklitsch, "Kolkbildung unter uberfallstrahlen. Diewasserwirtschaft," 1932.

[20] P. Novak, "Influence of bed load passage on scour and turbulence downstream of stilling basin," in Proceedings of the 9th Congress, IAHR, Dubrovnik, Croatia, 1961.

[21] D. Kotoulas, Das Kolkproblem unter Berüchsichtigung der Faktoren Zeit und Geschiebemischung im Rahmen derWildbachverbauung, Technical University of Braunschweig, Braunschweig, Germany, 1967.

[22] L. C. S. Pinto, Estudo teórico-experimental das pressões dinâmicas desenvolvidas no fundo de pré-escavações a jusante de estrutura tipo salto esqui. 1994. $376 \mathrm{f}$. Tese (Doutorado em Engenharia Hidráulica e Sanitária) - Escola Politécnica, Universidade de São Paulo, São Paulo, Brazil, 1994. 
[23] F. O. Lemos and C. M. Ramos, "Hydraulic modeling of free jet energy dissipation," in Proceedings of the Symposium on Scale Effects in Modelling Hydraulic Structures, Esslingen, Germany, 1987.

[24] L. Toombes and H. Chanson, "Free-surface aeration and momentum exchange at a bottom outlet," Journal of $\mathrm{Hy}$ draulic Research, vol. 45, no. 1, pp. 100-110, 2007.

[25] M. Pfister and W. H. Hager, "Deflector-generated jets," Journal of Hydraulic Research, vol. 47, no. 4, pp. 466-475, 2009.

[26] J. Borja, L. Silva, D. Sanagiotto, and M. Marques, "Energia residual a jusante de vertedouro tipo salto esqui," Revista Brasileira de Recursos Hídricos, vol. 18, no. 3, pp. 205-214, 2013b.

[27] S. Felder and H. Chanson, "Scale effects in microscopic airwater flow properties in high-velocity free-surface flows," Experimental Thermal and Fluid Science, vol. 83, pp. 19-36, 2017.

[28] E. Bollaert, Transient Water Pressures in Joints and Formation of Rock Scour Due to High-Velocity Jet Impact, Laboratory of Hydraulic Constructions, EPFL, Switzerland, 2002. 